Article

\title{
Reuse of Water in Laundry Applications with Micro- and Ultrafiltration Ceramic Membrane
}

\author{
Beatrice Dal Pio Luogo ${ }^{1} \mathbb{D}$, Toufic Salim ${ }^{2}$, Wenjing Zhang ${ }^{3}$, Nanna B. Hartmann ${ }^{3}$, Francesca Malpei ${ }^{1}$ \\ and Victor M. Candelario ${ }^{2, *}$ D
}

1 Politecnico di Milano, Department of Civil and Environmental Engineering (DICA)—Environmental Section, Piazza Leonardo da Vinci 32, 20133 Milano, Italy; bdalpioluogo@gmail.com (B.D.P.L.); francesca.malpei@polimi.it (F.M.)

2 Department of Research and Development, LiqTech Ceramics A/S, Industriparken 22C, 2750 Ballerup, Denmark; tsa@liqtech.com

3 Department of Environmental Engineering, Technical University of Denmark, Miljøvej 113, 2800 Kongens Lyngby, Denmark; wenz@env.dtu.dk (W.Z.); nibh@env.dtu.dk (N.B.H.)

* Correspondence: vcl@liqtech.com; Tel.: +45-3123-2944

check for updates

Citation: Luogo, B.D.P.; Salim, T.; Zhang, W.; Hartmann, N.B.; Malpei, F.; Candelario, V.M. Reuse of Water in Laundry Applications with Microand Ultrafiltration Ceramic

Membrane. Membranes 2022, 12, 223. https://doi.org/10.3390/

membranes 12020223

Academic Editor: Ahmad

Fauzi Ismail

Received: 20 October 2021

Accepted: 31 January 2022

Published: 15 February 2022

Publisher's Note: MDPI stays neutral with regard to jurisdictional claims in published maps and institutional affiliations.

Copyright: () 2022 by the authors Licensee MDPI, Basel, Switzerland. This article is an open access article distributed under the terms and conditions of the Creative Commons Attribution (CC BY) license (https:// creativecommons.org/licenses/by/ $4.0 /)$.

\begin{abstract}
This study compares the performance of a microfiltration membrane, made by silicon carbide $(\mathrm{SiC})$ and an ultrafiltration membrane, made by zirconia $\left(\mathrm{ZrO}_{2}\right)$, in the treatment of wastewater from a washing machine designed to clean industrial tents. The filtration of deionized water, containing model microplastics (i.e., nylon fiber), was performed. This was followed by the filtration of real wastewater from a single washing cycle of industrial tents, made from polyvinyl chloride (PVC) textile. The filtration parameters of the membranes and physical-chemical parameters of the wastewater, including the concentration of microplastics in the shape of tent fibers (PVC), were calculated before and after filtration. The microfiltration membrane manifested a greater decrease in permeability (95\%) compared to the ultrafiltration membrane $(37 \%)$. The resulting water quality in terms of Total Solids, turbidity, and microplastics concentration was better for the ultrafiltration. This is evident from $99.2 \%$ versus $98.55 \%$ removal efficiency of microplastics from the laundering wastewater, respectively.
\end{abstract}

Keywords: water reuse; industrial laundry; ceramic membrane

\section{Introduction}

Water scarcity and water contamination are among the most challenging global issues today. Water reuse plays an important role in solving this challenge. Adding to the conventional chemical pollutants, micro- and nano-plastic (MNPs) are prevalent in the environment, including in aquatic compartments. These contaminants pose an environmental, political, and social concern worldwide because they are ubiquitous and may result in chronic exposure due to their persistency in nature. MNPs can potentially work their way up through food chains in different ecosystems, as a consequence of both aquatic and terrestrial pollution. This, in turn, is partially due to the discharge of inadequately treated wastewater and the application of wastewater sludge on agricultural soils. Microplastics (MPs) can enter the environment readily in the form of MPs, or they can generate in the environment through the fragmentation of larger plastic items. It is estimated that $35 \%$ of the total amount of directly released MPs comes from the washing of synthetic textiles [1], making the discharge of MNPs from industrial laundry wastewater one of the biggest sources of MNPs to sewage and surface waters [2,3]. As society moves toward a circular economy by increasing wastewater reuse, there has become an urgent need to remove the MNPs from industrial laundry wastewater to allow for its reuse and to reduce the MNPs load on the receiving wastewater treatment plant (WWTP). However, the current industrial laundries are not capable of removing MNPs on site. An estimated $90 \%$ of industrial 
laundry wastewater discharges to sewage without adequate treatment, contributing to MNPs load in WWTP inlet water [4].

A study conducted by Magni et al. (2018) highlighted that a WWTP in Northern Italy releases 160,000,000 MPs / day to freshwater via treated effluents and 3,400,000,000 MPs/day to sewage sludge that is often reused as fertilizer in agriculture [5]. These numbers pose new issues for the regulation of biosolid disposal in the environment. The washing processes of synthetic textiles have been assessed as the main source of MPs [6-8], that enter the oceans [1,3-5]. Even if up to $99 \%$ of MPs are removed by wastewater treatment plants [9], some, especially the fiber-shaped ones, are released with the effluent $[2,10,11]$ and can pose a threat to ecosystems and human health [3]. For this reason, it is critical to increase the effectiveness of MPs removal at the washing machine discharge before they reach the WWTPs $[5,12]$. MPs can be separated from laundry wastewater by applying microfiltration membrane technologies. However, they are not capable of removing submicron-sized MNPs, so ultrafiltration could be the solution to remove these small contaminants.

Membrane-based technologies have been considered as an effective replacement for conventional water and wastewater treatment technologies, such as coagulation, flocculation, advanced oxidation processes, ion exchange, activated carbon adsorption, with the advantage of lower energy consumption, a smaller environmental impact, and efficient separation capability [13-15]. To remove MNPs, a microfiltration (MF)/ultrafiltration (UF) membrane-based filtration system can be proposed for laundry wastewater treatment. At present, the UF market is dominated by polymer membranes because of the low production cost. However, these polymer membranes typically suffer from swelling, biofouling, scaling and poor thermal and chemical resistance, which leads to a short lifespan and demands regular cleaning procedures. Besides, they may cause the release of constituent polymers, thus adding MNPs to permeate. On the contrary, ceramic membranes (e.g., $\mathrm{SiC}, \mathrm{ZrO}_{2}$, and $\mathrm{Al}_{2} \mathrm{O}_{3}$ ) benefit from higher chemical and physical stability. In particular, $\mathrm{SiC}$ is preferred over $\mathrm{Al}_{2} \mathrm{O}_{3}$ due to higher hydrophilicity resulting in high fluxes at low water pressures. This allows the $\mathrm{SiC}$-based filtration process to have a higher capacity and lower fouling potential than other materials [16-19]. In general, a long lifespan and lower maintenance of ceramic membranes lead to a significant reduction in OPEX and environmental impacts. Hence, ceramic membranes are far superior to polymer membranes for effluents of high temperature, harsh chemical environment, and containing abrasive particles, as seen in industrial laundry wastewater treatment.

The type of washing process investigated in this study is industrial laundering of tents made of PVC fabric. This material is chosen for being a water-resistant and durable material, making it suitable to cover outdoor structures. The specification of the industrial tent washing machine used in this study, are:

- $445 \mathrm{~kg}$ of tents washed/loaded (on average).

- Each machine runs on average 3.58 loads/day.

This implied that $1595 \mathrm{~kg}$ of tents can be washed per day. If a washing machine runs an average of 4.5 days/week, $7178 \mathrm{~kg}$ of tents is washed every week. Assuming that the fiber release behavior of PVC is similar to that of polyester (i.e., assuming a release of $150 \mathrm{mg}$ microplastics $/ \mathrm{kg}$ textile washed during the first washing cycle), resulting in an average of $1.08 \mathrm{~kg} /$ week of PVC microfibers would be released from one single industrial washing machine. If the wastewater does not undergo a proper treatment, addressing MP removal, these could potentially be released into the environment [6].

To remove solids from the laundering water, and to permitthe reuse of wastewater in the same washing process, a solution of membrane technologies can be used.

The present paper focuses on the comparison of two ceramic membranes made by $\mathrm{SiC}$ and by $\mathrm{ZrO}_{2}$. The membranes are in the micro- and ultra-filtration range, respectively, and are evaluated in terms of MNPs removal and membrane performance. Membranes were tested on a semi/pilot scale under real conditions. Structural characterization of the starting membrane was performed, and the effectiveness of the two membranes was measured by calculating different filtration parameters as critical flux, backflush period, and long-term 
filtration to evaluate the fouling effect of the membranes. A complete analysis of the feed and permeate water was performed, measuring turbidity, total suspended solids, volatile suspended solids, chemical oxygen demand, conductivity, $\mathrm{pH}$, total solids, total alkalinity, and microplastics.

\section{Materials and Methods}

Two different highly porous multichannel commercial ceramic membranes were used from LiqTech Ceramics A/S, Ballerup, Denmark, which consisted of 30 cylindrical channels with $3 \mathrm{~mm}$ diameter for each channel and $305 \mathrm{~mm}$ length, with an effective membrane area of $0.09 \mathrm{~m} 2$, a microfiltration membrane made by SiC support and $\mathrm{SiC}$ membrane (MF) and an ultrafiltration membrane made by $\mathrm{SiC}$ support and $\mathrm{ZrO} 2$ monoclinic membrane (UF). Membrane characterization was performed with Scanning Electron Microscopy (SEM), FlexSEM 1000 (Hitachi GmbH, Solna, Sweden) and Capillarity Flow Porosimetry (CFP), (3P Instruments, Odelzhausen, Germany) was carried out to measure the mean pore size and pore size distribution of the membranes of three samples from three different locations of the membrane. Before measurement, the pores of the membrane were filled with PorofilTM (fluorinated hydrocarbon) wetting liquid having a surface tension of $16 \mathrm{dyn} / \mathrm{cm}$. The wet curve was obtained by measuring the airflow rate through a sample with increasing pressure. Then, the dry curve was measured by increasing the air pressure using a dry membrane sample. A wet and dry curve was obtained, measuring the air flow rate using the sample with increasing pressure.

The filtration tests were all conducted on the commercial pilot-scale filtration set-up LiqTech LabBrain (LiqTech Ceramics A/S, Ballerup, Denmark) [17,18]. The unit was run with $1527 \mathrm{~L} / \mathrm{h}$ of crossflow and with $90 \%$ recovery. The retentate and the permeate were connected to the feed tank to perform recirculation.

Two different sets of experiments were conducted:

- Filtration of deionized water mixed with nylon microplastics obtained through cryogenic grinding (or cryogrinding) of red nylon fibers with $500 \mu \mathrm{m}$ length. This technique consists of freezing materials by pouring over liquid nitrogen $\left(-196^{\circ} \mathrm{C}\right)$ and then reducing it into a small particles size through milling (IKA A11 Basic Analytical mill). The length of MPs particles obtained was $80 \mu \mathrm{m}$, standard deviation: $\pm 39 \mu \mathrm{m}$.

- Filtration of wastewater from a single washing cycle of a PVC tent in an industrial washing machine.

Deionized water, deionized water plus $0.18 \mathrm{~g} / \mathrm{L}$ of Nylon fibers of $80 \mu \mathrm{m}$ and discharge from the first cycle of a washing machine of industrial tent laundering made of poly-vinylchloride (PVC) fabric (Hvalsø Teltudlejning ApS, Hvalsø, Denmark) were tested using the LabBrain equipment following the parameters mentioned before. The filtration steps are illustrated in Figure 1. The critical flux measurement was performed by testing with a gradual increase in the permeate flux and the transmembrane pressure was measured (TMP), with a holding time of $15 \mathrm{~min}$ in each step to achieve stabilization of the permeate flux and TMP. To control the deposition of solids on the membrane surface, back-flushing $(\mathrm{BF})$ of the membrane was performed, with the permeate feed at 3 bar pressure for $3 \mathrm{~s}$ duration. When the back-flushing permeate was pressed back through the membrane by a pump, the maximum interval that should be kept between each back-flush was investigated to achieve an optimal operation, with a stable flux and where only a small permeate consumption is required. To restore the original flux of the membrane, cleaning in place (CIP) of the system was performed with a combination of alkaline, Ultrasil 115 (Ecolab, København, Denmark) that consists of potassium hydroxide (10-20\%), sodium hydroxide (10-20\%), and ethylenediaminetetraacetate (5-10\%) and acids, Ultrasil 75 (Ecolab, København, Denmark), which is a mixture of nitric acid (10-30\%) and phosphoric acid (10-30\%), following the procedure mentioned by E. Eray et al. [17]. The benefit to industries that use CIP includes faster, less labor-intensive, and more repeatable cleaning, which poses a lower chemical exposure risk. With the right combination of chemicals, it is possible to dissolve as much of the foulant which will then leave the system easily. To confirm the 
recovery of the membrane, a deionized water permeability was measured after each CIP to be compared with the original one. Once the optimal parameters were obtained, the long-term filtration was performed by setting up the parameters for $96 \mathrm{~h}$.

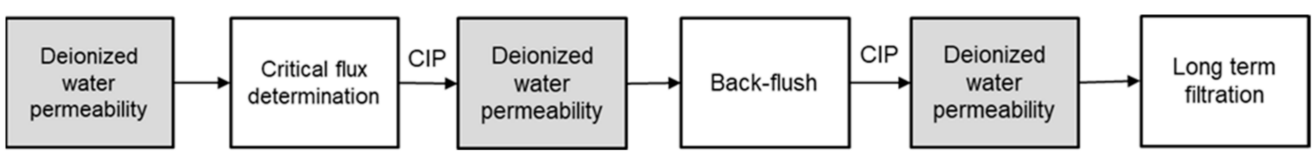

Figure 1. Filtration test plan.

The feed water and the permeate after the filtration experiments were characterized concerning the main water quality physical-chemical parameters such as $\mathrm{pH}$, conductivity, turbidity, total alkalinity (TAL), total solids (TS), total suspended solids (TSS), volatile suspended solids (VSS), chemical oxygen demand (COD) were calculated with the method illustrated in Table 1 . Then, the water was characterized in terms of the presence of microplastics.

Table 1. Water characterization parameters and instruments used.

\begin{tabular}{ccc}
\hline Parameter & Unit & Instrument/Method \\
\hline $\mathrm{pH}$ & - & $\mathrm{pH}$ probe HQ40D (Hach, Loveland, CO, USA) \\
Turbidity & $\mathrm{NTU}$ & Turbidimeter TN-100 (Thermo Scientific Eu, Bufalo, NY, USA) \\
Conductivity & $\mathrm{uS} / \mathrm{cm}$ & Conductivity meter EC400 model ExStik \\
TDS & $\mathrm{mg} / \mathrm{L}$ & Weighting and drying filter at $105^{\circ} \mathrm{C}$ \\
$\mathrm{TSS}$ & $\mathrm{mg} / \mathrm{L}$ & Weighting and drying water sample at $105^{\circ} \mathrm{C}$ \\
$\mathrm{VSS}$ & $\mathrm{mg} / \mathrm{L}$ & Weighting and drying water sample at $500^{\circ} \mathrm{C}$ \\
TAL & $\mathrm{mg} / \mathrm{L}$ & Titration with sulfuric acid \\
COD & $\mathrm{mg} / \mathrm{L}$ & Cuvette test for COD, 15-150 $\mathrm{mg} / \mathrm{L} \mathrm{O}_{2}$ \\
\hline
\end{tabular}

To determine the concentration of MPs, a sample of $20 \mathrm{~mL}$ was filtered through a $5 \mu \mathrm{m}$ pore size filter, and light microscopy was applied to detect microplastics in the sample. Observing the filter at the microscope, the prevalence of particles other than MPs was immediately evident. Hence, a pretreatment with hydrogen peroxide to remove organic matter and improve MP detection. For this purpose, $1 \mathrm{~mL} \mathrm{H}_{2} \mathrm{O}_{2}$ was added to a $20 \mathrm{~mL}$ sample and incubated at $20^{\circ} \mathrm{C}$. The fibers were imaged and measured using QCapture Pro software; The test was repeated three times, and the fibers were detected through visual counting. The filter was divided into a grid, as shown in Figure 2, which made it easier to count square by square. To speed up the counting, only 12 squares were chosen in a well-distributed manner, each having an area of $0.25 \mathrm{~cm}^{2}$. The average number of microplastics counted per square was multiplied by the total number of squares on the filter. The total area of the filter was $23.74 \mathrm{~cm}^{2}$, corresponding to 94.94 squares.

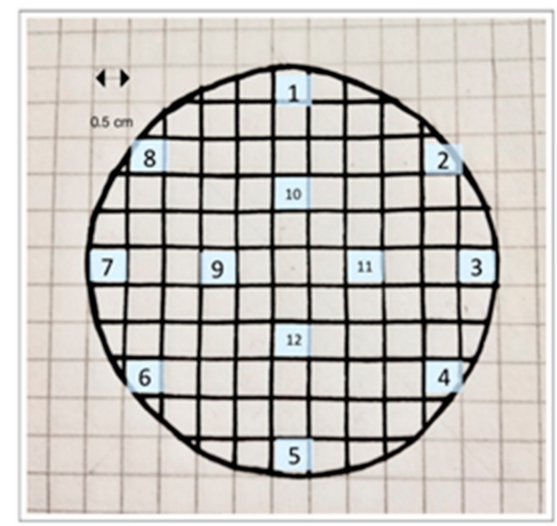

Figure 2. Scheme used for the visual counting of microplastics. 


\section{Results}

\subsection{Membrane Characterization}

Figure $3 \mathrm{~A}, \mathrm{C}$ shows the SEM images of the selective layer and Figure 3B,D of the membrane cross-section. As it is possible to see by the results of the two membranes, the UF had a thicker layer and the smaller pore size compared to MF. The layer thickness of MF and UF were $\sim 68 \mu \mathrm{m}$ and $\sim 87 \mu \mathrm{m}$, respectively. Both samples had a homogeneous surface without defects and good adhesion of the grains.
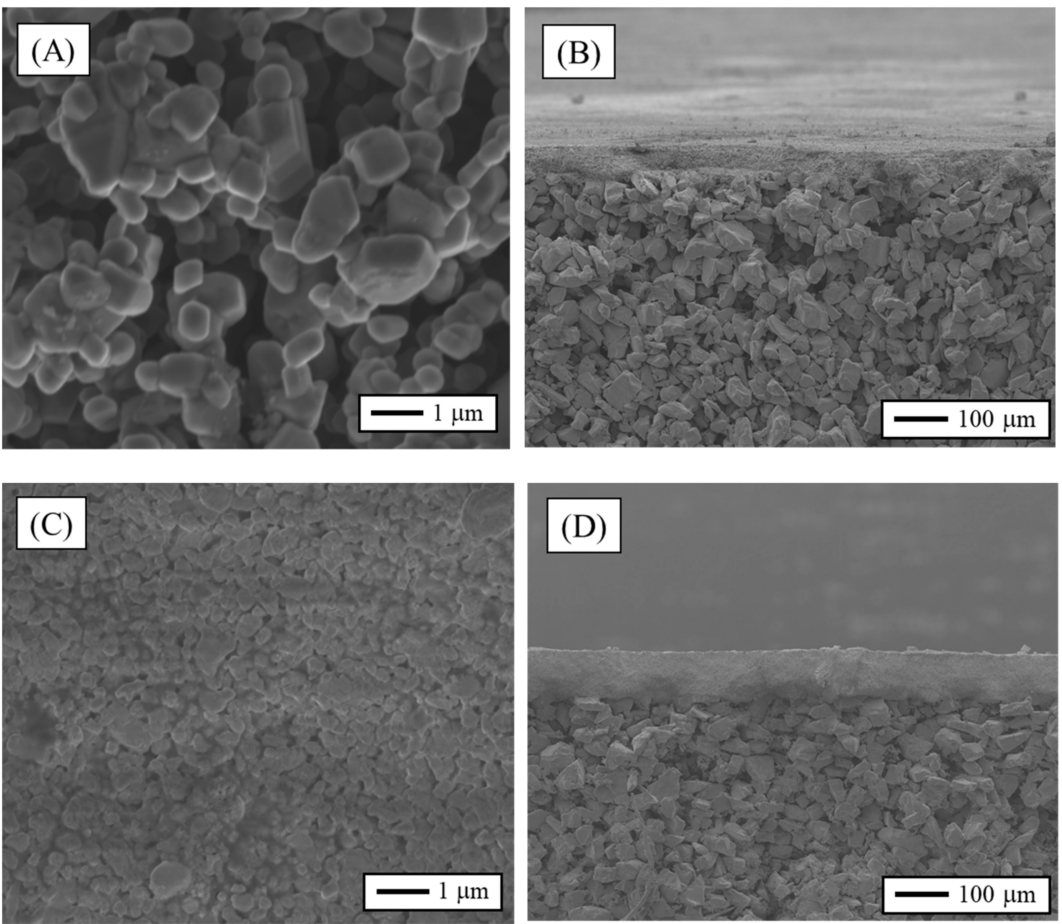

Figure 3. Results of SEM, selective layer (A) MF (C) UF, cross-section (B) MF (D) UF.

This difference in pore-size range and distribution was also confirmed quantitatively from the results of Capillary Flow Porosimetry, visible in Figure 4 and Table 2. The average values of the maximum $\mathrm{d}_{90}$ and $\mathrm{d}_{50}$ pore size from the three samples (middle, left, and right part of a tubular membrane) was calculated for both membranes. As it is possible to see from Table 2, 90\% of the pores in MF were below $302 \mathrm{~nm}$, while for UF they were below $63 \mathrm{~nm}$, resulting in one order of magnitude of difference between the size of the pores in the two membranes. These tests confirmed that MF is in the microfiltration range and the UF is in the ultrafiltration range, as indicated by the supplier.
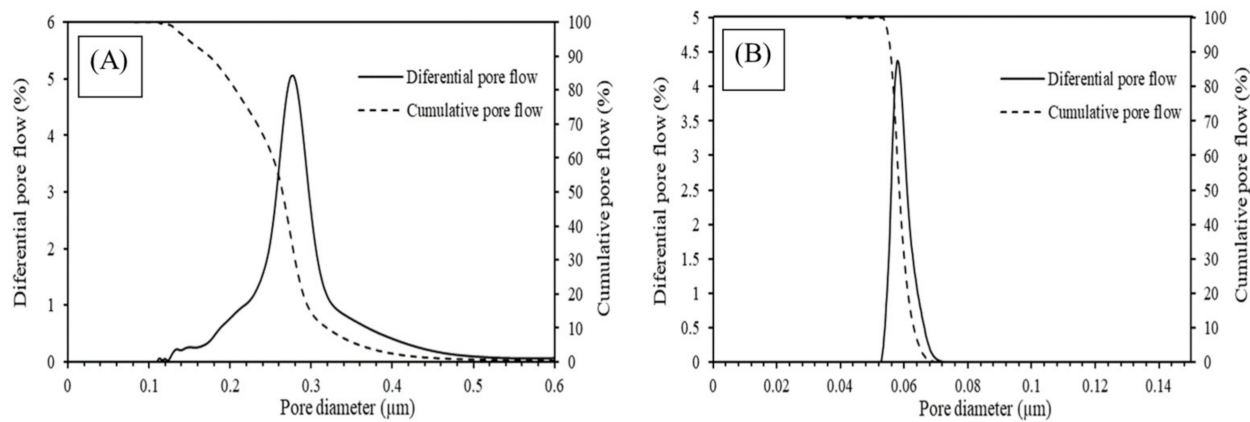

Figure 4. Results of the pore-size distribution of (A) MF (B) UF. 
Table 2. Results of Capillarity Flow Porosimetry.

\begin{tabular}{cccc}
\hline Membrane & Maximum Pore Size $(\mathbf{n m})$ & d90 $(\mathbf{n m})$ & d50 $(\mathbf{n m})$ \\
\hline MF & 604 & 302 & 247 \\
UF & 74 & 63 & 58 \\
\hline
\end{tabular}

\subsection{Synthetic Feed}

The performance of the two different membranes was studied first in controlled conditions, with a synthetic feed prepared by mixing $0.18 \mathrm{~g} / \mathrm{L}$ of nylon fibers $(80 \mu \mathrm{m})$ in deionized water to facilitate the analysis of the microplastic removal studying the behavior of the flux vs. the TMP and analyzing the permeate in both cases.

Prior to the start of the test with the synthetic water, the permeability of the membrane in deionized water was determined. Figure 5 shows the variation of the permeate flux vs. the transmembrane pressure of the deionized water. From the slope of the linear fit of the experimental data, the deionized water permeability can be calculated as $\sim 3400 \mathrm{~L} /\left(\mathrm{m}^{2} \cdot \mathrm{h} \cdot \mathrm{bar}\right)$ for the MF and $\sim 327 \mathrm{~L} /\left(\mathrm{m}^{2} \cdot \mathrm{h} \cdot \mathrm{bar}\right)$ for the UF. The intercept with the y-axis is different from zero in both graphs, and this may be because of the osmotic pressure, of which an initial pressure is necessary to overcome, as well as pressure originated from the pressure drop within the membrane pore [20]. The permeability is also in the range of the micro and ultrafiltration membrane, respectively, for both membranes.
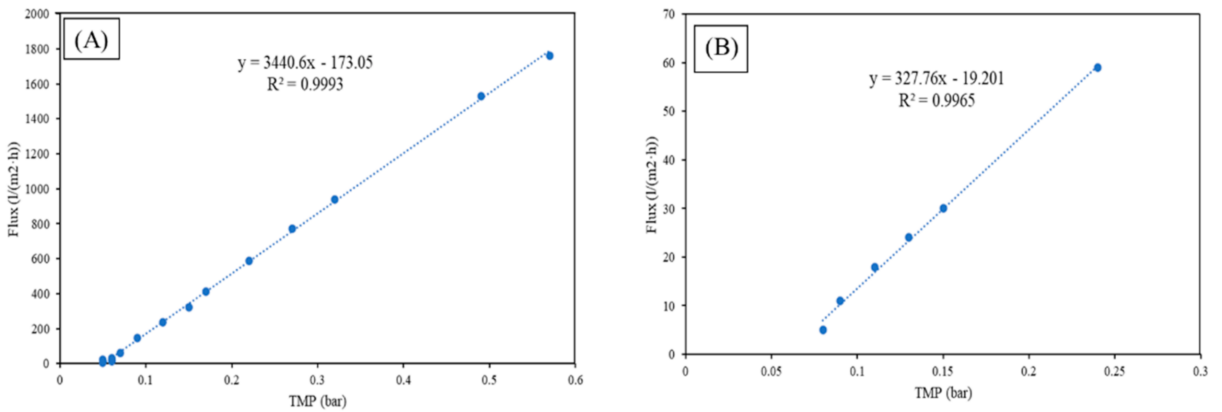

Figure 5. Permeate flux vs. transmembrane pressure of the deionized water for (A) MF and (B) UF.

Figure 6 shows permeate flux vs. the transmembrane pressure of the synthetic feed. A loss of flux occurs in the case of MF but not with the UF. In fact, by plotting TMP vs. the flux for the MF and by plotting the tendency line (in orange), which is obtained by interpolating the lower points and represents the behavior that the membrane would have in the case of clean water, it is possible to see that the empirical data, with an increase in the flux, reach a high TMP rapidly and no longer overlaps with the tendency line. This means that the MF undergoes a loss of flux. Hence, it is possible to calculate the critical flux for the MF filtrating small microplastics, which is $\sim 200 \mathrm{~L} /\left(\mathrm{m}^{2} \cdot \mathrm{h}\right)$. In both cases, the number of microplastics in the permeate was evaluated with a $100 \%$ removal.
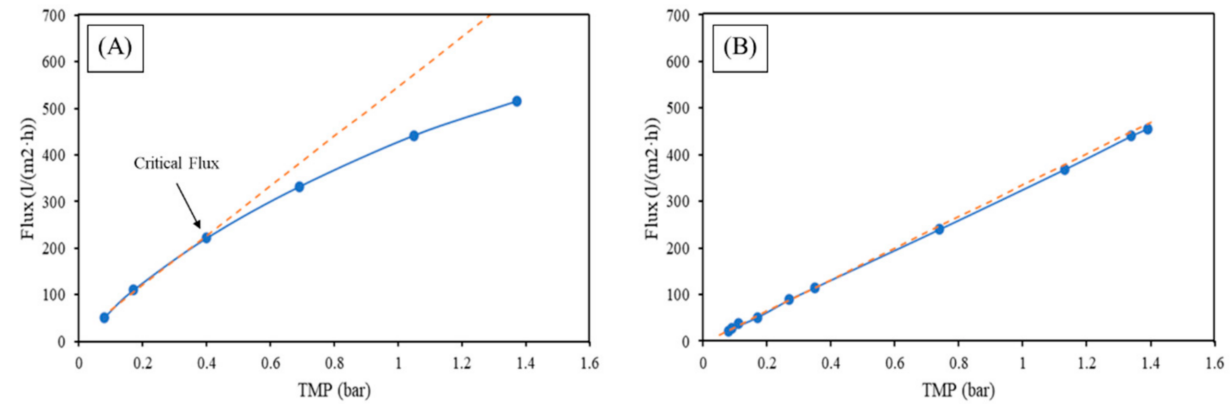

Figure 6. Filtration test with $0.18 \mathrm{~g} / \mathrm{L}$ small microplastics (A) MF (B) UF. Where the orange line is theoretical for deionized water. 
Even though both membranes presented a full rejection of the microplastics, the presence of the synthetic fibers in the synthetic feed affected the permeability of the microfiltration membranes, leading to the establishment of the critical flux value, differently from the UF membranes. Comparing the size of membrane pores and microplastics particles, it can be assumed that pore-blocking occurred in the MF membrane, possibly generating irreversible long-term fouling.

\subsection{Wastewater from Washing Machine of Industrial Tent Laundering \\ 3.3.1. Filtration Experiments}

Critical flux is the first parameter calculated to evaluate the performance of the microand ultra-filtration membranes with the real feed.

Figure 7 shows the experimental values and the linear fit of the first point describing the behavior of the membrane in case of no loss of flux (as with deionized water flux), and the conjunction of these two lines is the critical flux, which is defined as the threshold flux below which irreversible fouling does not occur, and above which fouling becomes noticeable. In both cases, the tendency line (in red) diverges from the experimental line (blue).
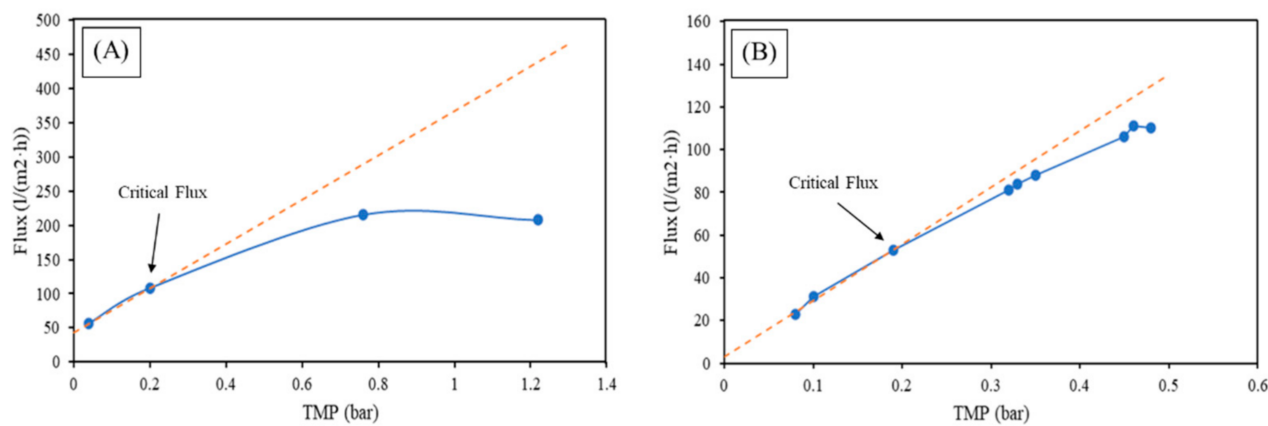

Figure 7. Critical flux determination of feed from the first cycle of a washing machine of industrial tent laundering (A) MF (B) UF. Where the orange line is theoretical for deionized water.

The critical flux corresponds to the point of separation between the red line (tendency line) and the blue line (empirical data). For MF, the critical flux that results is $100 \mathrm{~L} /\left(\mathrm{m}^{2} \cdot \mathrm{h}\right)$. As is possible to see in Figure $7 \mathrm{~A}$, in the case of UF, the critical flux is $55 \mathrm{~L} /\left(\mathrm{m}^{2} \cdot \mathrm{h}\right)$, also indicated in Figure 7B.

Once the critical flux is calculated, the backflush interval can be determined. Hence, with a constant value of flux, chosen below the critical flux, the backflush interval was obtained. For the microfiltration membrane, a constant flux of $90 \mathrm{~L} /\left(\mathrm{m}^{2} \cdot \mathrm{h}\right)$ was set, and for the ultrafiltration membrane, $50 \mathrm{~L} /\left(\mathrm{m}^{2} \cdot \mathrm{h}\right)$ was set.

For the MF, the initial TMP of 0.19 bar was recovered with a back-flush (BF) time set after $30 \mathrm{~min}$. A second BF was set after $60 \mathrm{~min}$, resulting in a higher TMP compared with the initial one. During the subsequent run of $60 \mathrm{~min}$, the TMP increased and was not recoverable by back-flush. As is visible in Figure $8 \mathrm{~A}$, after a BF interval of $1 \mathrm{~h}$, the TMP became too high, and the $\mathrm{BF}$ could not revert it to its original state. Therefore, $\mathrm{BF}$ for the long term must be set to $20 \mathrm{~min}$, a value just below the BF interval where the TMP can be recovered, to ensure that in long term filtration the permeability with BF without the use of CIP can be recovered. For the UF, after $30 \mathrm{~min}$, the BF could completely recover the initial TMP, which was 0.37 bar, after 90 min of running at a constant flow without BF the TMP was slightly higher, while after a BF interval of $3 \mathrm{~h}$, the TMP became too high, and the $\mathrm{BF}$ could not be restored to the original one. Hence, the BF time must be set to $1 \mathrm{~h}$ for long-term filtration. 

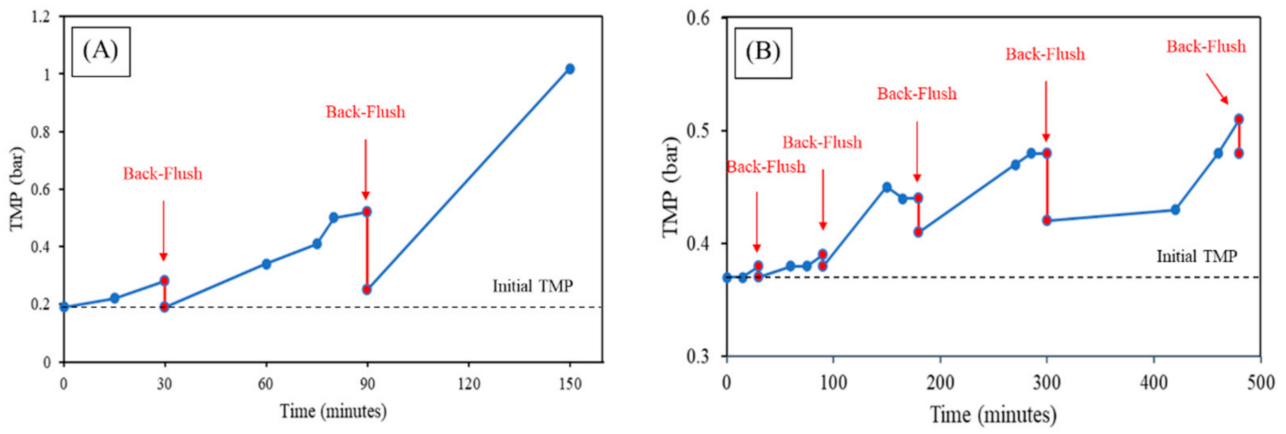

Figure 8. Back-flush time determination (A) MF and (B) UF.

Because of the larger pores in the microfiltration membrane, the backflush period for MF should be lower than for UF, to avoid irreversible fouling. After determining the critical flux and the back-flush time, the unit was set to perform the long term filtration at optimal conditions.

The long-term filtration consisted of recirculating the wastewater through the membrane for 4 days, and the permeability, recorded every $30 \mathrm{~min}$, is shown in Figure 9 . The settings were based on the previous experiments, with the following parameters: (i) for MF a constant permeate flux of $90 \mathrm{~L} /\left(\mathrm{m}^{2} \cdot \mathrm{h}\right)$ and backflush every $20 \mathrm{~min}$, (ii) for the UF a constant permeate flux of $50 \mathrm{~L} /\left(\mathrm{m}^{2} \cdot \mathrm{h}\right)$ and backflush every $60 \mathrm{~min}$. Despite both membranes filtrating at their optimal conditions, the MF underwent a great decrease in permeability of $\sim 95 \%$, while for the UF the permeability loss was less accentuated, at $\sim 37 \%$, for the same period of filtration.
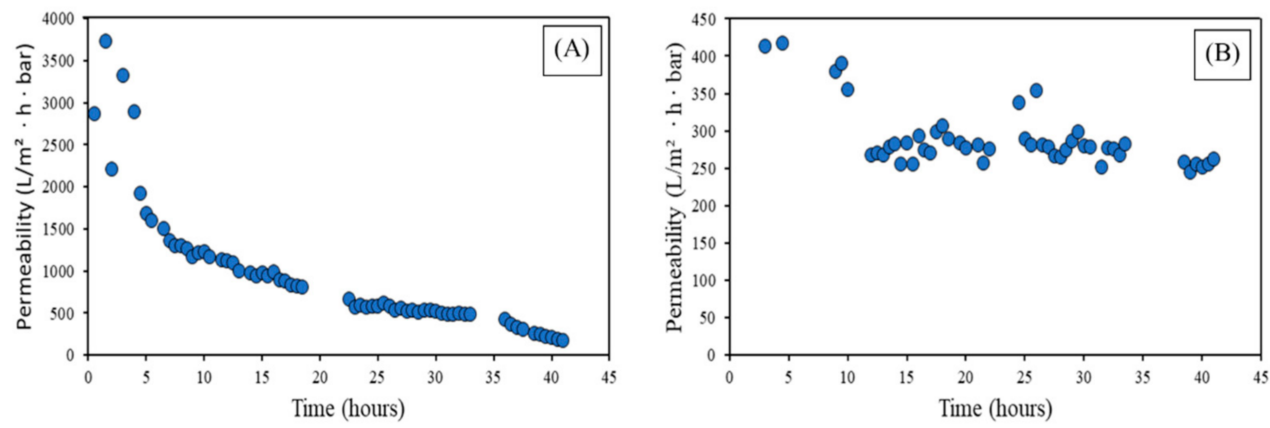

Figure 9. Long-term experiment, permeability vs. time (A) MF (B) UF.

The use of the UF will provide better performance during filtration and less BF during the time, with less permeability loss and avoiding the clogging of the membrane during a longer period. The MF will need to undergo CIP more often than the UF, and the operational cost will be higher in the case of microfiltration membranes.

\subsubsection{Physical-Chemical Analysis of Water after Filtration}

Table 3 reports the removal efficiencies of the most significant parameters involved in the definition of water quality. The first aspect that is noticeable both qualitatively and quantitatively is the transparency of the permeate, whereby the wastewater feed was very black and dusty, while both permeate streams are clear when observed by the naked eye. This visual improvement is also confirmed by the measurement of turbidity, which changed from 206 NTU of the feed to 10.3 NTU in the MF permeate (and 1.01 NTU in the UF permeate. It can be noticed that the $\mathrm{pH}$ did not change to a significant degree after filtration. In the feed, it was 6.8, and for MF permeate, it remained around neutrality (7.06), while for the UF permeate, it became slightly alkaline (8.36), as can be easily noticed by observing the Total Alkalinity of the feed $(5.77 \mathrm{meq} / \mathrm{L})$ and of the UF permeate $(8.53 \mathrm{meq} / \mathrm{L})$, which is higher, while TAL of the MF permeate was $6.81 \mathrm{meq} / \mathrm{L}$, this change can be due to the 
cleaning process. Furthermore, the UF membrane could absorb some alkalinity from the $\mathrm{CIP}$ and increase the $\mathrm{pH}$ slightly. Conductivity remains more or less the same before and after filtration, around $800 \mu \mathrm{S} / \mathrm{cm}$. This could be predictable since the membrane is not capable of retaining salts. What presents a significant variation, as expected, is the solid matter contained in the wastewater, especially in terms of TSS and VSS. Total suspended solids were $221.67 \mathrm{mg} / \mathrm{L}$ in the feed, while after filtration with MF they become $52.5 \mathrm{mg} / \mathrm{L}$ (76.3\% efficiency of removal), and with UF they become $9 \mathrm{mg} / \mathrm{L}$ (95.9\% removal). This difference in the removal efficiency is explained by the physical separation mechanism performed by the membranes. In the case of UF, it has smaller pores on its selective layer, at $50 \%$ below $42.6 \mathrm{~nm}$, so it is capable of removing more solids than the MF, which has larger pores (at $50 \%$ below $247.2 \mathrm{~nm}$ ). Focusing on the Total dissolved solids, in the wastewater, a negligible reduction was observed for MF filtration (feed: $737 \mathrm{mg} / \mathrm{L}$, permeate: $731 \mathrm{mg} / \mathrm{L}$ ), and a $20 \%$ reduction in concentration was observed for UF filtration. The reduction of TDS can be explained by the higher capability of the UF membrane to retain organic and inorganic substances in colloidal forms. Further treatment, such as Reverse Osmosis (RO) or Forward Osmosis (FO), could be required to reduce TDS. Regarding the organic matter contained in the water, Volatile Suspended Solids changed from $121.67 \mathrm{mg} / \mathrm{L}$ in the feed to $25 \mathrm{mg} / \mathrm{L}$ in the MF permeate (the removal occurred with 79\% efficiency) while they are negligible in the UF permeate. The Chemical Oxygen Demand in the wastewater feed was $424 \mathrm{mg} / \mathrm{L}$, while in the MF permeate, it was $84.3 \mathrm{mg} / \mathrm{L}$, and in the UF permeate, it was $68.7 \mathrm{mg} / \mathrm{L}$. In general, the UF membrane achieved a better removal of Turbidity, TSS, VSS, and COD, because of its small pores in its selective layer.

Table 3. The removal efficiency of the main wastewater parameters.

\begin{tabular}{ccc}
\hline & Removal Efficiency (\%) & \\
\hline Parameter & MF & UF \\
\hline Turbidity & 95 & 99.5 \\
TSS & 76.3 & 95.9 \\
VSS & 79 & 100 \\
COD & 80 & 83.8 \\
microplastics & 98.5 & 99.2 \\
\hline
\end{tabular}

The characterization of the water quality then focused on the microplastics, by calculating the average number of microplastics found in $20 \mathrm{~mL}$ of wastewater feed by visual counting through light microscopy. The number of microplastics found can be approximated to around 900 microplastics for $20 \mathrm{~mL}$, thus corresponding to 45,000 microplastics/L. Supposing the average volume of 1 single microplastic to be $353 \times 10^{-9} \mathrm{~cm}^{3}$ (based on an average length of $0.5 \mathrm{~mm}$, a radius of $0.015 \mathrm{~mm}$, and a cylindric geometry), and assuming a density of PVC in the range $1.40-1.45 \mathrm{~g} / \mathrm{cm}^{3}$, the weight of a single microplastic can be approximated to $503 \times 10^{-9} \mathrm{~g}$. Therefore, the concentration in the mass of MPs in the wastewater feed would correspond to $22.6 \mathrm{mg} / \mathrm{L}$. This is a value comparable to $20.5 \mathrm{mg} / \mathrm{L}$ of fibers, released after the 1st washing cycle according to a previous study [1]. After filtration, the number of microplastics found in the permeate from filtration with the MF membrane was 1250 microplastics $/ \mathrm{L}$, with a concentration of $0.3 \mathrm{mg} / \mathrm{L}$, meaning that the microfiltration membrane was able to remove $98.5 \%$ of microplastic particles from the laundering wastewater. A similar calculation was performed for the microplastics found in the permeate from the filtration with the UF membrane, resulting in 450 microplastics/L, with a concentration of $0.135 \mathrm{mg} / \mathrm{L}$. This value is very low and means that the percentage of removal of microplastics for this membrane is around $99.2 \%$. In both cases, almost all microplastics have been removed, with higher efficiency of the UF membrane, probably because of the smaller pore size. 


\section{Conclusions}

In the present work, a comparison of two ceramic membranes (MF and UF) was performed, with the aim to (1) evaluate their capability to retain MPs and (2) to evaluate the effect of the presence of MPS on membrane fouling. Tests were conducted with a synthetic feed (deionized water + MPs) and with real wastewater from the 1st washing cycle of an industrial laundry application. The key findings are summarized as follows:

- From the membrane characterization, it was found that both membranes had a defectfree and homogeneous surface. Furthermore, the membrane made by $\mathrm{SiC}$ was in the microfiltration range, with $\mathrm{d}_{90}$ of $\sim 302 \mathrm{~nm}$, whereas the membrane made using $\mathrm{ZrO}_{2}$ was in the ultrafiltration range, with a $\mathrm{d}_{90}$ of $\sim 52 \mathrm{~nm}$.

- The filtration of the synthetic feed with nylon fibers of $80 \mu \mathrm{m}$ showed a critical flux value, in the case of $\mathrm{MF}$, of $200 \mathrm{~L} /\left(\mathrm{m}^{2} \cdot \mathrm{h}\right)$. This demonstrates an effect of MPs in terms, most probably, of pore blocking. With the capabilities of the unit, it was not possible to obtain a critical flux for the UF, because no reduction of flux was observed along with the increasing TMP cycles. There is a clear indication that the fouling occurs earlier in MF compared to UF. In both cases, a $100 \%$ rate of removal of the fibers was achieved.

- With the filtration of the real wastewater from the tent laundry outlet, the critical flux value and backflush period for the MF was $90 \mathrm{~L} /\left(\mathrm{m}^{2} \cdot \mathrm{h}\right)$ with a $20 \mathrm{~min}$ period and $50 \mathrm{~L} /\left(\mathrm{m}^{2} \cdot \mathrm{h}\right)$ and $60 \mathrm{~min}$ period for the UF. After 4 days of constant filtration, there was a considerable decrease in the permeability of MF ( 95\%), while much smaller in the case of UF $(\sim 37 \%)$. Therefore, the better performance of UF in real applications can be established, with a lower necessity of CIP and longer operation periods.

- $\quad$ Based on the water analysis of the feed and permeate during the long-term filtration of both membranes, we can conclude that the UF results in better water quality in the permeate compared to the $\mathrm{MF}$, with almost a $100 \%$ rate of removal in all studied parameters. The results obtained in this study pave the way for future wastewater treatment systems for industrial laundries, where the UF ceramic membranes can be used as the polishing step to remove MPs before being reused or discharged into the municipal wastewater stream.

Author Contributions: Conceptualization, B.D.P.L., W.Z. and V.M.C.; methodology, B.D.P.L. and V.M.C.; formal analysis, B.D.P.L., W.Z., N.B.H., F.M. and V.M.C.; investigation, B.D.P.L. and T.S.; data curation, W.Z. and V.M.C.; writing—original draft preparation, B.D.P.L. and V.M.C.; writing—review and editing, B.D.P.L., W.Z., N.B.H., F.M. and V.M.C.; supervision, W.Z., N.B.H., F.M. and V.M.C.; project administration W.Z. and V.M.C.; funding acquisition V.M.C. All authors have read and agreed to the published version of the manuscript.

Funding: This research received no external funding.

Institutional Review Board Statement: Not applicable.

Informed Consent Statement: Not applicable.

Data Availability Statement: Not applicable.

Conflicts of Interest: The authors declare no conflict of interest.

\section{References}

1. Boucher, J.; Friot, D. InternatIonal UnIon for ConservatIon of NatUre a Global Evaluation of Sources Primary Microplastics in the Oceans. 2017. Available online: https:/ / portals.iucn.org/library/sites/library/files/documents/2017-002-En.pdf (accessed on 19 October 2021).

2. Cai, Y.; Yang, T.; Mitrano, D.M.; Heuberger, M.; Hufenus, R.; Nowack, B. Systematic Study of Microplastic Fiber Release from 12 Different Polyester Textiles during Washing. Environ. Sci. Technol. 2020, 54, 4847-4855. [CrossRef] [PubMed]

3. Napper, I.E.; Thompson, R.C. Release of Synthetic Microplastic Plastic Fibres from Domestic Washing Machines: Effects of Fabric Type and Washing Conditions. Mar. Pollut. Bull. 2016, 112, 39-45. [CrossRef] [PubMed]

4. Hoinkis, J.; Panten, V. Wastewater Recycling in Laundries-From Pilot to Large-Scale Plant. Chem. Eng. Process. Process Intensif. 2008, 47, 1159-1164. [CrossRef] 
5. Magni, S.; Binelli, A.; Pittura, L.; Avio, C.G.; della Torre, C.; Parenti, C.C.; Gorbi, S.; Regoli, F. The Fate of Microplastics in an Italian Wastewater Treatment Plant. Sci. Total Environ. 2019, 652, 602-610. [CrossRef] [PubMed]

6. De Falco, F.; di Pace, E.; Cocca, M.; Avella, M. The Contribution of Washing Processes of Synthetic Clothes to Microplastic Pollution. Sci. Rep. 2019, 9, 6633. [CrossRef] [PubMed]

7. Pirc, U.; Vidmar, M.; Mozer, A.; Kržan, A. Emissions of Microplastic Fibers from Microfiber Fleece during Domestic Washing. Environ. Sci. Pollut. Res. 2016, 23, 22206-22211. [CrossRef] [PubMed]

8. De Falco, F.; Gullo, M.P.; Gentile, G.; di Pace, E.; Cocca, M.; Gelabert, L.; Brouta-Agnésa, M.; Rovira, A.; Escudero, R.; Villalba, R.; et al. Evaluation of Microplastic Release Caused by Textile Washing Processes of Synthetic Fabrics. Environ. Pollut. 2018, 236, 916-925. [CrossRef] [PubMed]

9. Talvitie, J.; Mikola, A.; Setälä, O.; Heinonen, M.; Koistinen, A. How well is microlitter purified from wastewater?-A detailed study on the stepwise removal of microlitter in a tertiary level wastewater treatment plant. Water Res. 2017, 109, 164-172. [CrossRef] [PubMed]

10. Gatidou, G.; Arvaniti, O.S.; Stasinakis, A.S. Review on the Occurrence and Fate of Microplastics in Sewage Treatment Plants. J. Hazard. Mater. 2019, 367, 504-512. [CrossRef] [PubMed]

11. Edo, C.; González-Pleiter, M.; Leganés, F.; Fernández-Piñas, F.; Rosal, R. Fate of Microplastics in Wastewater Treatment Plants and Their Environmental Dispersion with Effluent and Sludge. Environ. Pollut. 2020, 259, 113837. [CrossRef] [PubMed]

12. Wright, S.L.; Kelly, F.J. Plastic and Human Health: A Micro Issue? Environ. Sci. Technol. 2017, 51, 6634-6647. [CrossRef] [PubMed]

13. Kaegi, R.; Voegelin, A.; Ort, C.; Sinnet, B.; Thalmann, B.; Krismer, J.; Hagendorfer, H.; Elumelu, M.; Mueller, E. Fate and Transformation of Silver Nanoparticles in Urban Wastewater Systems. Water Res. 2013, 47, 3866-3877. [CrossRef] [PubMed]

14. Kamali, M.; Suhas, D.P.; Costa, M.E.; Capela, I.; Aminabhavi, T.M. Sustainability Considerations in Membrane-Based Technologies for Industrial Effluents Treatment. Chem. Eng. J. 2019, 368, 474-494. [CrossRef]

15. Goh, P.S.; Ismail, A.F. A Review on Inorganic Membranes for Desalination and Wastewater Treatment. Desalination 2018, 434, 60-80. [CrossRef]

16. Hofs, B.; Ogier, J.; Vries, D.; Beerendonk, E.F.; Cornelissen, E.R. Comparison of Ceramic and Polymeric Membrane Permeability and Fouling Using Surface Water. Sep. Purif. Technol. 2011, 79, 365-374. [CrossRef]

17. Eray, E.; Boffa, V.; Jørgensen, M.K.; Magnacca, G.; Candelario, V.M. Enhanced Fabrication of Silicon Carbide Membranes for Wastewater Treatment: From Laboratory to Industrial Scale. J. Membr. Sci. 2020, 606, 118080. [CrossRef]

18. Bortot Coelho, F.E.; Kaiser, N.N.; Magnacca, G.; Candelario, V.M. Corrosion Resistant ZrO2/SiC Ultrafiltration Membranes for Wastewater Treatment and Operation in Harsh Environments. J. Eur. Ceram. Soc. 2021, 41, 7792-7806. [CrossRef]

19. Eray, E.; Candelario, V.M.; Boffa, V.; Safafar, H.; Østedgaard-Munck, D.N.; Zahrtmann, N.; Kadrispahic, H.; Jørgensen, M.K. A Roadmap for the Development and Applications of Silicon Carbide Membranes for Liquid Filtration: Recent Advancements, Challenges, and Perspectives. Chem. Eng. J. 2021, 414, 128826. [CrossRef]

20. Cancino, B.; Ulloa, L.; Astudillo, C. Osmotic Pressure of Salt and Sugar Solutions: Its Influence on Reverse Osmosis in the Food Industry. Inf. Tecnol. 2009, 20, 55-64. [CrossRef] 